\title{
Demographic history shapes genetic variability in cryptic fish species of high ecologic and economic relevance
}

\author{
Jessika Neves ${ }^{1}$, Zachary Nolen ${ }^{2}$, Nidia Fabre ${ }^{1}$, Tamí Mott ${ }^{1}$, and Ricardo Pereira ${ }^{2,3}$ \\ ${ }^{1}$ Universidade Federal de Alagoas \\ ${ }^{2}$ Ludwig Maximilians University Munich \\ ${ }^{3}$ Ludwig-Maximilians-Universität München
}

May 27, 2020

\begin{abstract}
Human overexploitation of natural resources has placed conservation and management as one of the most pressing challenges in modern societies, particularly regarding highly vulnerable marine ecosystems. Although a large effort has been made to design Marine Protected Areas (MPAs) worldwide, it is still unclear how many species actually exist in these MPAs, what is the genetic connectivity between areas with different protective regimes, and what is their relative genetic diversity. We answer these questions using morphologically cryptic species of the genus Mugil that are sympatric in the largest MPA in the Tropical Southwestern marine province. Population structure analyses show the existence of five highly divergent species (FST $>0.855)$ and no genetic divergence between two estuaries with different protection status (FST $=0.005)$. Sympatric individuals are assigned to single clusters and show strong concordance among hundreds of independent gene trees, consistent with full reproductive isolation and no ancestral nor ongoing hybridization. Differences of genetic diversity within species suggest that effective population sizes differ up to two-fold, probably reflecting differences in the magnitude of population expansions during the evolutionary history of these species, rather than recent impact of fisheries. Together, our results suggest that designing MPAs with areas of integral protection in between areas where fisheries are permitted could be an effective way to manage cryptic species that cannot have species-specific quotas. More generally, this work shows a cost-efficient approach that is transferable to other marine or terrestrial organisms of special concern, helping to implement science-based regulations for management and conservation.
\end{abstract}

\section{Hosted file}

Mugil_NGS_molecol.pdf available at https://authorea.com/users/326665/articles/454479demographic-history-shapes-genetic-variability-in-cryptic-fish-species-of-high-ecologicand-economic-relevance 

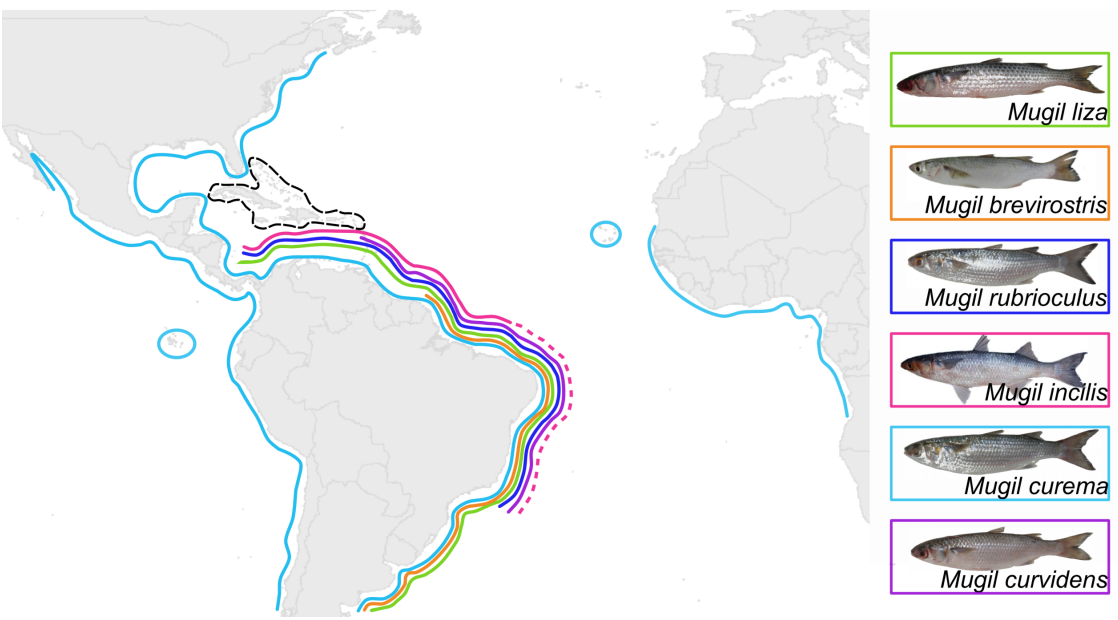

A)
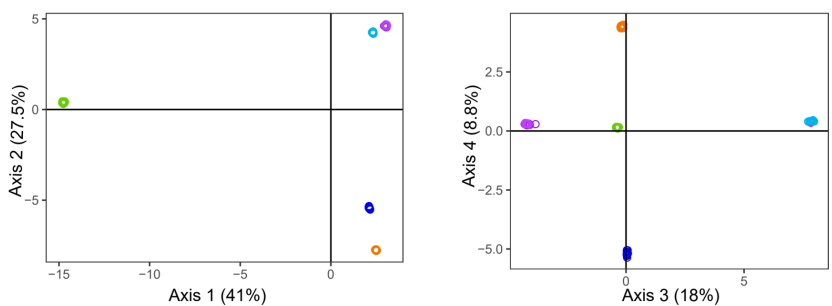

M. liza

M. brevirostris

- M. rubrioculus

- $M$. incilis

M. curema

M. curvidens (SA)
M. curvidens (MB)

B)

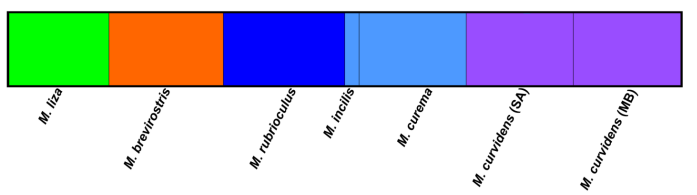

A)

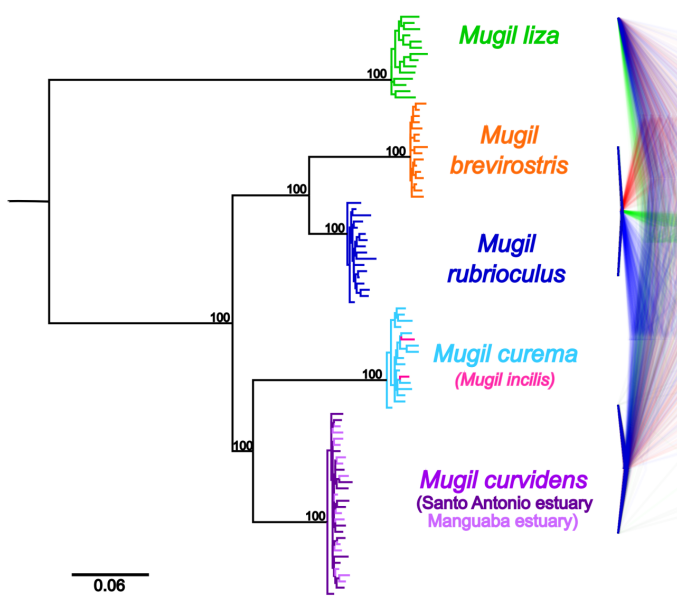

B) 
A)

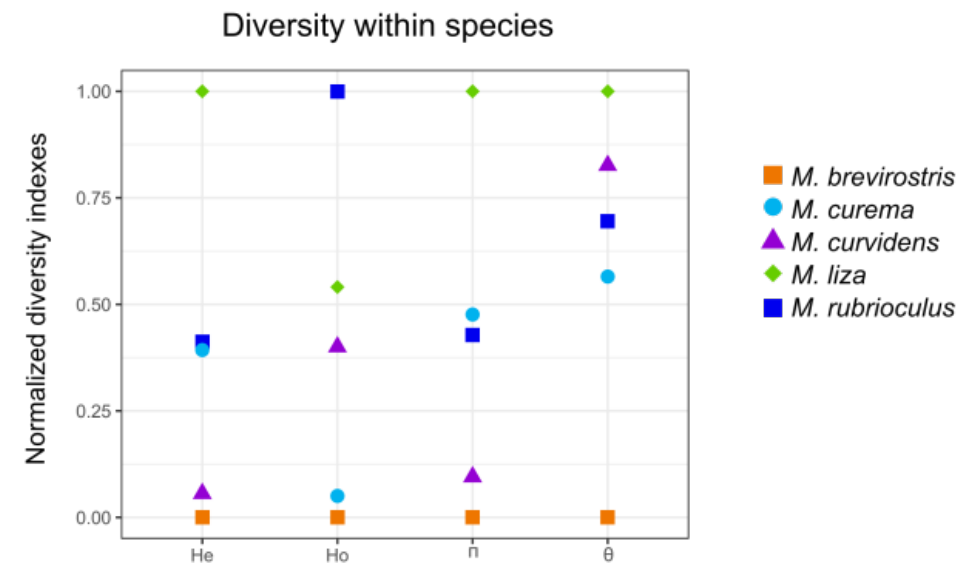

B)

Demographic neutrality
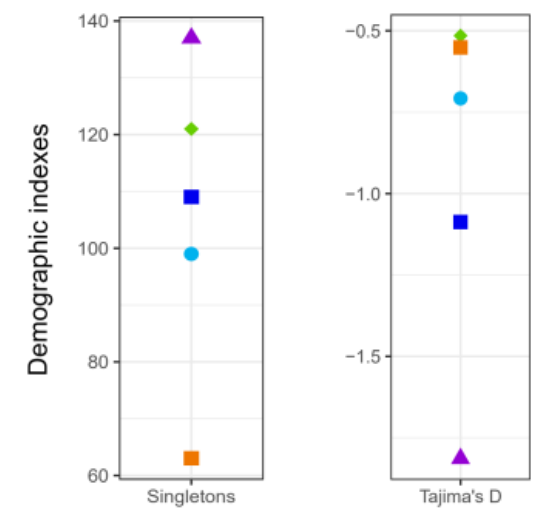

C)

Demographic models

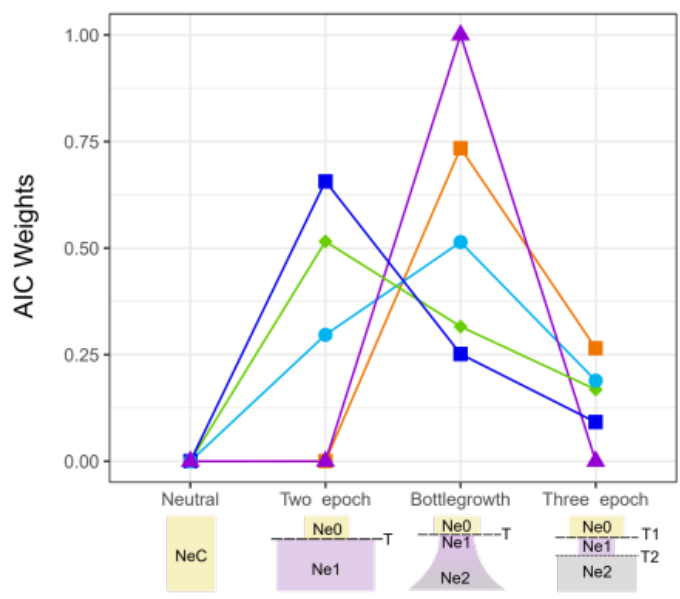

